\title{
Age and growth of the smooth hammerhead shark, Sphyrna zygaena, in the Eastern Equatorial Atlantic Ocean, using vertebral sections
}

\author{
Rui Coelho ${ }^{1,2, a}$, Joana Fernandez-Carvalho ${ }^{1}$, Sérgio Amorim ${ }^{1}$ and Miguel N. Santos ${ }^{1}$ \\ 1 Instituto Nacional dos Recursos Biológicos IP/ IPIMAR, 8700-305 Olhão, Portugal \\ 2 Centro de Ciências do Mar, Universidade do Algarve, Portugal
}

Received 31 January 2011; Accepted 19 July 2011

\begin{abstract}
The smooth hammerhead shark Sphyrna zygaena (Sphyrnidae) is regularly caught as bycatch in pelagic longline fisheries, but is one of the least studied of all pelagic sharks. Recently, ICCAT (International Commission for the Conservation of Atlantic Tunas) issued recommendations underlining the need for more studies on the life history parameters of this and other pelagic shark species. To this end, the age and growth of S. zygaena were studied in the Eastern Equatorial Atlantic Ocean, in an area where growth parameters were not yet available for this species. Data from 139 specimens, caught between June and September 2009, ranging in size from 136 to $233 \mathrm{~cm}$ fork length (FL), were analysed. Preliminary trials were carried out to assess the most efficient growth band enhancement technique. These indicated that sectioning the vertebrae into $500 \mu \mathrm{m}$ sections followed by staining with crystal violet produced the best results. Growth models were fitted using the traditional von Bertalanffy growth equation and a modification of this equation using a known size at birth. Growth models were compared using the Akaike information criterion (AIC). The von Bertalanffy growth equation seemed to be the most adequate model to describe growth in this species, with resulting growth parameters of $L_{\text {inf }}=272 \mathrm{~cm} \mathrm{FL}, k=0.06$ year for males and $L_{\text {inf }}=285 \mathrm{~cm} \mathrm{FL}, k=0.07$ year for females. In the first four years of life, $S$. zygaena grows $25 \mathrm{~cm}$ per year on average, but its growth slows down in later life. Future stock assessment models should incorporate these age and growth parameters for species management and conservation.
\end{abstract}

Key words: Age and growth / pelagic longline fisheries / life history / Carcharhiniformes / vertebral band counts / Atlantic Ocean

\section{Introduction}

Elasmobranch fishes have gained increased importance as fishery resources in recent years (Barker and Schluessel 2005). These fishes are exploited by directly targeted fisheries and caught as bycatch in fisheries targeting other species (Stevens et al. 2000). Oceanic sharks pose a particularly difficult problem when it comes to fisheries management and conservation due to their highly migratory nature that leads them to migrate between territorial waters of different countries and international waters. Moreover, elasmobranchs generally have Kstrategy life cycles characterized by slow growth rates and low reproductive potential (Cortés 2000). These life history traits make them extremely vulnerable to fishing pressure, with overexploitation occurring even at relatively low levels of fishing mortality (Smith et al. 1998).

The smooth hammerhead shark, Sphyrna zygaena (Linnaeus 1758), is a cosmopolitan pelagic hammerhead shark occurring from close inshore to offshore oceanic waters

\footnotetext{
${ }^{a}$ Corresponding author: rpcoelho@ualg.pt
}

(Compagno 1984). As with other pelagic shark species, S. zygaena is commonly caught as bycatch by pelagic longlines targeting swordfish in the Eastern Equatorial Atlantic, even though it is caught in much lower numbers than the considerably more common blue shark (Prionace glauca) and mako shark (Isurus oxyrinchus) (Buencuerpo et al. 1998).

Despite being regularly caught as bycatch by these commercial fisheries, information on life history, movement patterns, essential habitats, and population dynamics of this species is still scarce over most of its range. While other species of large pelagic hammerheads, such as the scalloped hammerhead (Sphyrna lewini), have been the focus of several population dynamics studies (e.g., Branstetter 1987; Chen et al. 1990; Anislado-Tolentino and Mendoza 2001; Piercy et al. 2007; Anislado-Tolentino et al. 2008; Harry et al. 2011), almost no information is currently available on the life history parameters of $S$. zygaena.

Cortés et al. (2010) conducted an ecological risk assessment for eleven species of pelagic elasmobranchs in the Atlantic Ocean and concluded that $S$. zygaena appeared to be 




Fig. 1. Map of the Eastern Equatorial Atlantic with the location of the Sphyrna zygaena samples. Dark circles represent males and light grey circles represent females.

among the less vulnerable, probably due to its relatively high fecundity compared with other oceanic sharks (29 to 37 young per litter, according to (Compagno 1984)). However, Cortés (2010) also mentioned that S. zygaena was one of the species for which there is the most urgent need of better biological data, due to many uncertainties regarding its life history. Furthermore, it is probable that significant and under-reported fishing mortality of this and other hammerhead species is taking place in large-scale longline fisheries, as the fins of hammerhead sharks are highly prized on Asian markets (Clarke et al. 2006).

In the Atlantic Ocean, the International Commission for the Conservation of Atlantic Tunas (ICCAT) is the intergovernmental fishery organization responsible for the management and conservation of migratory tunas and tuna-like species, including pelagic sharks such as $S$. zygaena. Recent concerns about the lack of knowledge on life history parameters of these sharks has led ICCAT to issue several resolutions and recommendations stating the need for more studies focused on these aspects (e.g., ICCAT 2003, 2004; 2007).

Therefore, the main objective of the present study was to present information on the age and growth of S. zygaena in the Eastern Equatorial Atlantic Ocean. Because there is still great uncertainty about which techniques are most suitable for estimating age in this species, a secondary objective was to assess and compare several different growth band enhancement techniques

\section{Materials and methods}

\subsection{Biological sampling}

Samples for this study were collected by INRB, I.P./ IPIMAR (Portuguese Institute of Marine Research) fishery observers aboard Portuguese longliners targeting swordfish in the Atlantic Ocean. Samples for this specific study were collected from the Eastern Equatorial Atlantic (latitudes $7^{\circ} \mathrm{N}$ to $1^{\circ} \mathrm{S}$; longitudes $8{ }^{\circ} \mathrm{E}$ to $23^{\circ} \mathrm{W}$ ) between June and September 2009 (Fig. 1).

Once brought aboard, the sharks were identified, sexed and measured for fork length (FL) to the nearest $\mathrm{cm}$. A sample of 4 to 8 vertebrae from the anterior region of the carcass (directly behind the head) was removed and stored frozen. These samples were then transported to the laboratory where they were further cleaned and processed. Once in the laboratory, the vertebrae were cleaned: first by manually removing most of the organic tissue with scalpels and then by immersion in bleach (sodium hypochlorite solution). General purpose commercial bleach was used, typically containing $4 \%$ to $6 \%$ sodium hypochlorite. After cleaning, the vertebrae were dried, mounted on a microscope slide with thermoplastic cement, and sectioned along the longitudinal plane as described by Goldman (2004). For sectioning the vertebrae, a Buehler Isomet slow speed cutting machine was used; cutting sections of approximately $500 \mu \mathrm{m}$ thickness. Different vertebral section thicknesses, specifically $300 \mu \mathrm{m}, 500 \mu \mathrm{m}$, and $700 \mu \mathrm{m}$, had already been tested in a preliminary trial. As the $500 \mu \mathrm{m}$ thickness produced the best results, it was chosen for the present study.

\subsection{Comparison of ageing techniques}

Because no previous literature is available for estimating the age and growth of this species, preliminary trials for growth band visualization were carried out on vertebrae from 30 randomly selected individuals, using several common techniques for ageing elasmobranch fishes: whole vertebrae $\mathrm{X}$ rays (Cailliet et al. 1983) and examination of vertebral sections, either unstained or coloured with crystal violet (Johnson 1979) or alizarin red (LaMarca 1966). To compare the different growth band enhancement techniques, both the coefficient of variation (CV) (Chang 1982) and the average percent error (APE) (Beamish and Fournier 1981) were calculated and compared between techniques. 
The visualization of the vertebral sections was carried out under a dissecting microscope using transmitted white light. Opaque and translucent bands were identified following the description and terminology described by Cailliet and Goldman (2004). For each vertebra of each specimen, three independent readings and age estimations were carried out by two readers. Age estimation was only assigned to a specimen if the recordings made by the two readers were consistent and gave the same age estimation.

\subsection{Age estimation and growth modelling}

The relationship between the size of the specimens and the size of their vertebrae was determined. The vertebral sections were micro-photographed using a dissecting microscope and the vertebral radius of the vertebrae was digitally measured using Image J software (Abramoff et al. 2004). The Pearson product-moment correlation coefficient between the vertebral radius and FL was estimated. A linear regression was fitted using FL as the dependent variable and the vertebral radius as the independent variable. The coefficient of determination $\left(\mathrm{R}^{2}\right)$ of this linear regression was determined, and the significance of the regression tested by ANOVA $\left(\mathrm{H}_{0}\right.$ : slope parameter of the regression $\left.\left(\beta_{1}\right)=0\right)$.

To model the growth of $S$. zygaena, both the traditional von Bertalanffy growth model (VBGF) and a modified VBGF with fixed size at birth (VBGF with fixed $\left.L_{0}\right)$ were fitted and compared.

von Bertalanffy growth model (VBGF):

$$
L_{t}=L_{i n f}\left(1-e^{-k\left(t-t_{0}\right)}\right)
$$

Modified VBGF with fixed size at birth (fixed $L_{0}$ ):

$$
L_{t}=L_{i n f}\left(1-b e^{-k t}\right)
$$

where $b=\left(L_{\text {inf }}-L_{0}\right) / L_{\text {inf }}$

$L_{t}$ : mean size $(\mathrm{FL}, \mathrm{cm})$ at age $t$ (year); $L_{\text {inf }}$ : asymptotic maximum size (FL);

$L_{0}$ : size $(\mathrm{FL}, \mathrm{cm})$ at birth; $k$ : growth coefficient $\left(\mathrm{year}^{-1}\right) ; t_{0}$ : theoretical age (year) at zero size.

The fixed sizes at birth $\left(L_{0}\right)$ used in the second equation were the minimum and the maximum values of size at birth described for the species by Compagno (1984): 50 and $61 \mathrm{~cm}$ total length (TL), respectively. Because size data in our study refers to FL (136 to $233 \mathrm{~cm}$ ), we used the following equation to convert the size at birth from TL into FL:

$\mathrm{FL}=12.72+0.84 \mathrm{TL}$

$\left(n=257 ; R^{2}=0.95 ;\right.$ SE intercept $\left(\beta_{0}\right)=2.92 ;$ SE slope $\left(\beta_{1}\right)=0.01$; Regression ANOVA: $\left.F=5214 ; p<0.01\right)($ INRB I.P./ IPIMAR, unpublished data).

All growth models were fitted using the R package ( $R$ Development Core Team, 2010), with parameters estimated using nonlinear least-squares (NLS). For each growth model, the parameters, their corresponding standard error (SE) and the lower and upper limits of the $95 \%$ confidence intervals were estimated. Model goodness of fit, comparison and selection were based on the Akaike information criterion (AIC), with the best model defined as the one having the lowest AIC value

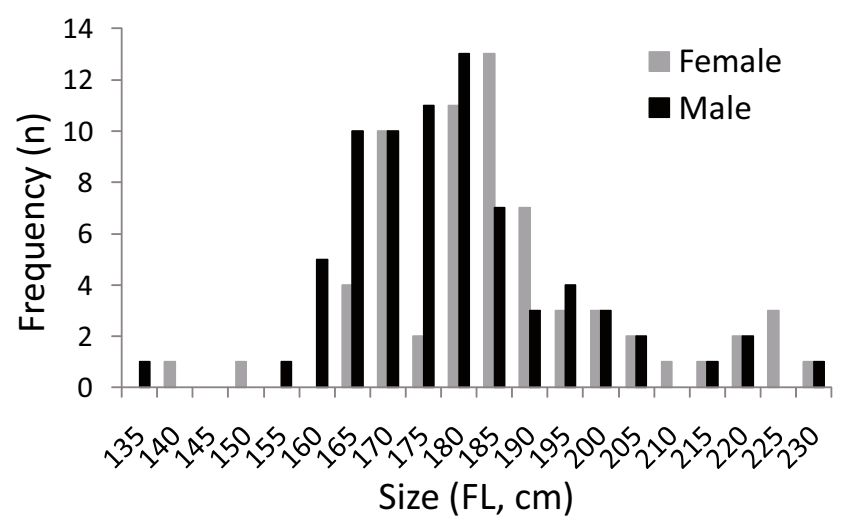

Fig. 2. Size (fork length) frequency distribution of male $(n=74)$ and female $(n=65)$ Sphyrna zygaena caught in the eastern equatorial Atlantic Ocean, between June and September 2009. Sizes are grouped in $5 \mathrm{~cm}$ fork length classes.

(Katsanevakis 2006). The differences between the best model and alternative candidate models $\left(\Delta_{i}\right)$ were calculated, and provided a measure of the adequacy of the alternative models. A likelihood ratio test, as defined by Kimura (1980) and recommended by Cerrato (1990), was used to test the null hypothesis that there were no differences in the growth parameters of males and females.

\section{Results}

\subsection{Sample characteristics}

A total of 139 samples (74 males and 65 females) were collected and analysed for this study. Females ranged in size between 140 and $233 \mathrm{~cm}$ FL (mean \pm standard deviation: $187.3 \pm 17.9 \mathrm{~cm}$ ), while males ranged in size between 136 and $230 \mathrm{~cm}$ FL $(180.8 \pm 15.7 \mathrm{~cm})$. Most of the specimens caught (73\% of the sample) were between $160 \mathrm{~cm}$ and $190 \mathrm{~cm} \mathrm{FL}$ (Fig. 2).

\subsection{Comparison of ageing techniques}

The technique of sectioning the vertebrae followed by staining with crystal violet was the most consistent for estimating the age of S. zygaena. Both the CV and the APE indexes were lower with the crystal violet stain than with alizarin red, and much lower than results obtained by attempting to count growth bands on unstained vertebral sections (Table 1). $\mathrm{X}$-raying whole vertebrae did not provide satisfactory results and this technique was not tested further. In terms of the influence of different techniques on age estimation, there was a tendency for crystal violet to give the highest age estimates, followed by alizarin red and finally the unstained sections.

Additionally, using the crystal violet resulted in more vertebrae having a final assigned age. Of the 30 vertebrae that were used for the preliminary trial, all vertebral sections that had been stained with crystal violet had at least 2 out of 3 readings with the same age estimation (i.e., all these recordings 
Table 1. Precision indexes for band enhancing techniques tested for ageing Sphyrna zygaena. CV refers to the coefficient of variation and APE to the average percent error. Accepted readings (in \%) refer to the \% that would have been acceptable to use in the growth model, i.e., those that had at least 2 out of 3 consistent age estimations. $n=30$ specimens / vertebrae tested per technique.

\begin{tabular}{llll}
\hline \multirow{2}{*}{ Technique } & \multicolumn{2}{l}{ Precision index } & \multirow{2}{*}{ Accepted readings (\%) } \\
\cline { 2 - 3 } & CV & APE & \\
\hline Crystal violet & 5.0 & 5.8 & 100 \\
Alizarin red & 6.5 & 7.3 & 83 \\
No staining & 8.1 & 8.9 & 67 \\
\hline
\end{tabular}



Fig. 3. Microphotograph of a vertebral section of Sphyrna. zygaena, with the identification of the birth mark (b) and 10 growth bands.

could have been used for the growth models), while that percentage decreased to $83 \%$ with alizarin red stain and to $67 \%$ for the sections left unstained (Table 1). Therefore, the technique of slicing the vertebrae into $500 \mu \mathrm{m}$ sections and staining them with crystal violet seems to be the most appropriate for $S$. zygaena, and was applied to the remaining specimens used in the study (Fig. 3).

\subsection{Age estimation and growth modelling}

Pearson product moment correlation was high (0.93) between specimen size and vertebral radius (VR) where the growth bands were counted. The linear regression between FL (cm) and VR (mm) was defined by:

$$
\mathrm{FL}=53.16+11.63 \mathrm{VR}
$$

$\left(n=139 ;\right.$ SE intercept $\left(\beta_{0}\right)=4.31 ;$ SE slope $\left(\beta_{1}\right)=0.38$; $\left.R^{2}=0.87\right)$,

and was highly significant (regression ANOVA: $F=938$; $p<0.001)$.

In general, the vertebral sections stained with crystal violet were relatively easy to read, and a clear pattern of alternating translucent and opaque bands was visible. It was possible to age 138 out of the 139 specimens initially processed. The single specimen that could not be aged had vertebrae with very poor band discrimination, and was therefore discarded from the analysis.

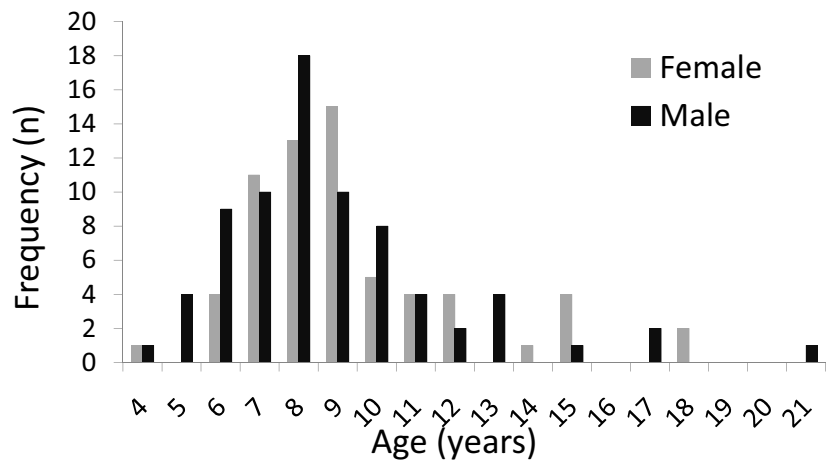

Fig. 4. Age distributions of male and female Sphyrna zygaena $(n=$ 138).

Estimated ages ranged from 4 to 21 years in males, and from 4 to 18 years in females (Fig. 4). The younger specimens (age 4) had sizes of 136 and $140 \mathrm{~cm}$ FL. Considering that size at birth was estimated at 29 to $39 \mathrm{~cm}$ FL, these specimens grew approximately $25 \mathrm{~cm}$ FL per year on average during those initial years of life.

The growth models were calculated and plotted separately for each sex (Fig. 5), revealing significant differences between males and females (likelihood ratio test: $\chi^{2}=11.86, d f=3$, $p=0.008$ ). The $L_{\text {inf }}$ values estimated with the VBGF tended to be higher than those estimated with the VBGF with fixed $L_{0}$, while the $k$ parameters tended to be lower (Table 2). The differences between using a fixed size at birth of 29 or $39 \mathrm{~cm}$ FL produced minimal differences in the estimated $L_{\text {inf }}$ and $k$ parameters (Table 2). In terms of model goodness of fit, the AIC values were better (lower) for the growth curves estimated with the VBGF.

\section{Discussion}

Because no previous age and growth studies are known for S. zygaena, the first step of the present work was to assess which band enhancement technique would produce the best results for estimating ages in this species. Cailliet (1983) underlines the importance of such preliminary analyses, particularly for species where no previous studies have ever been carried out. The observation of growth bands in the vertebral sections of $S$. zygaena was generally easy for most of our samples, particularly after applying the crystal violet stain. Alizarin red stain produced acceptable results but these were generally poorer than those obtained with crystal violet. On the other hand, trying to count growth bands without any band 



Fig. 5. Observed ages and estimated growth models (in fork length) for male and female Sphyrna zygaena.

enhancement technique (vertebral sections left unstained) or analysing X-rays of whole vertebrae was much more difficult, as there was poor contrast between the opaque and translucent bands in these cases.

As a baseline, Campana (2001) suggested reference levels of $7.6 \%$ for $\mathrm{CV}$ and $5.5 \%$ for APE, but mentioned that most studies reporting shark ages based on vertebrae had $\mathrm{CV}$ values exceeding $10 \%$. In our preliminary trials, both crystal violet and alizarin red results had values lower that these reference levels suggested by Campana (2001). Additional advantages of the crystal violet technique are that it is very simple and fast to apply and has a lower cost. Other authors have used this technique on hammerhead sharks of the same genus (Sphyrna), namely the scalloped hammerhead (S. lewini) (Piercy et al. 2007) and great hammerhead (S. mokarran) (Piercy et al. 2010).

Because this is the first approach to modelling the growth of $S$. zygaena, it was important to examine and compare different growth models, and we chose to compare the traditional VBGF with a modified VBGF using a fixed $L_{0}$ (size at birth). In general, the $k$ values were higher and the $L_{\text {inf }}$ values were lower when using the VBGF with known $L_{0}$ instead of the traditional VBGF. In terms of model goodness of fit, the AIC values were lower for the VBGF than for the VBGF using a fixed $L_{0}$.

Even though this is the first known age and growth study for $S$. zygaena in the Atlantic Ocean, other closely related species have already been studied, such as the scalloped hammerhead in the NW Atlantic Ocean and Gulf of Mexico (Branstetter 1987; Piercy et al. 2007), off NE Taiwan (Chen et al. 1990) and off Mexico in the Eastern Pacific (AnisladoTolentino and Mendoza 2001; Anislado-Tolentino et al. 2008). The growth coefficients ( $k$ values) estimated in these studies ranged from minima of 0.073 (sexes combined) in the Gulf of Mexico (Branstetter 1987) to 0.222 (males) and 0.249 (females) off NE Taiwan (Chen et al. 1990). Even though no 
Table 2. Growth parameters ( $L_{\text {inf }} \mathrm{FL} \mathrm{cm}, k$ year ${ }^{-1}$ and $t_{0}$ year) for Sphyrna zygaena (sexes combined and separate) from the Eastern Equatorial Atlantic, obtained with the von Bertalanffy growth function (VBGF) and the VBGF with fixed $L_{0}(29$ and $39 \mathrm{~cm}$ FL). For each model, parameters are presented with the respective standard errors (SE) and 95\% confidence intervals (CI). Model goodness of fit is given by the Akaike information criterion (AIC).

\begin{tabular}{|c|c|c|c|c|c|c|}
\hline \multirow{2}{*}{ Sex } & \multirow{2}{*}{ Model } & \multirow{2}{*}{ Parameter } & \multirow{2}{*}{ Estimate } & \multirow{2}{*}{ SE } & \multicolumn{2}{|c|}{$95 \% \mathrm{CI}$} \\
\hline & & & & & Lower & Upper \\
\hline \multirow{7}{*}{ Sexes combined } & \multirow{3}{*}{ VBGF, $\mathrm{AIC}=932$} & $L_{\text {inf }}$ & 277.7 & 24.4 & 229.6 & 325.9 \\
\hline & & $k$ & 0.06 & 0.02 & 0.03 & 0.10 \\
\hline & & $t_{0}$ & -8.3 & 2.1 & -12.5 & -4.0 \\
\hline & \multirow{2}{*}{ VBGF $L_{0}=29 \mathrm{~cm}, \mathrm{AIC}=971$} & $L_{\text {inf }}$ & 220.2 & 2.8 & 214.7 & 225.7 \\
\hline & & $k$ & 0.20 & 0.01 & 0.18 & 0.21 \\
\hline & \multirow{2}{*}{$\mathrm{VBGF} L_{0}=39 \mathrm{~cm}, \mathrm{AIC}=965$} & $L_{i n f}$ & 222.3 & 2.93 & 216.5 & 228.1 \\
\hline & & $k$ & 0.18 & 0.01 & 0.17 & 0.20 \\
\hline \multirow{7}{*}{ Males } & \multirow{3}{*}{$\mathrm{VBGF}, \mathrm{AIC}=482$} & $L_{\text {inf }}$ & 271.8 & 29.2 & 213.5 & 330.0 \\
\hline & & $k$ & 0.06 & 0.02 & 0.02 & 0.10 \\
\hline & & $t_{0}$ & -9.4 & 2.9 & -15.1 & -3.7 \\
\hline & \multirow{2}{*}{ VBGF $L_{0}=29 \mathrm{~cm}, \mathrm{AIC}=514$} & $L_{i n f}$ & 212.2 & 3.2 & 205.8 & 218.7 \\
\hline & & $k$ & 0.22 & 0.01 & 0.20 & 0.24 \\
\hline & \multirow{2}{*}{$\mathrm{VBGF} L_{0}=39 \mathrm{~cm}, \mathrm{AIC}=510$} & $L_{\text {inf }}$ & 214.1 & 3.4 & 207.4 & 220.9 \\
\hline & & $k$ & 0.20 & 0.01 & 0.18 & 0.23 \\
\hline \multirow{7}{*}{ Females } & \multirow{3}{*}{ VBGF, AIC $=443$} & $L_{\text {inf }}$ & 285.2 & 41.3 & 202.7 & 367.7 \\
\hline & & $k$ & 0.07 & 0.03 & 0.01 & 0.13 \\
\hline & & $t_{0}$ & -7.3 & 3.3 & -13.9 & -0.8 \\
\hline & \multirow{2}{*}{$\mathrm{VBGF} L_{0}=29 \mathrm{~cm}, \mathrm{AIC}=452$} & $L_{i n f}$ & 229.2 & 4.6 & 219.9 & 238.3 \\
\hline & & $k$ & 0.18 & 0.01 & 0.16 & 0.20 \\
\hline & \multirow{2}{*}{$\mathrm{VBGF} L_{0}=39 \mathrm{~cm}, \mathrm{AIC}=450$} & $L_{i n f}$ & 231.5 & 4.9 & 221.7 & 241.3 \\
\hline & & $k$ & 0.17 & 0.01 & 0.15 & 0.19 \\
\hline
\end{tabular}

direct comparison can be made between different species, the values that were estimated for S. zygaena in the present study seem to fall at the lower end of these ranges presented previously for the scalloped hammerhead. Elasmobranch fishes generally have long lives and slow growth rates (Cortés 2000). In the present case, such slow growth rates make $S$. zygaena particularly vulnerable to overexploitation.

Compagno (1984) described the size at birth of $S$. zygaena as between 50 and $61 \mathrm{~cm}$ TL, which corresponds to 29 to $39 \mathrm{~cm}$ FL after conversion. Considering that the younger specimens in the present study were two specimens of age 4 with sizes of 136 and $140 \mathrm{~cm}$ FL, this means that these specimens grew on average approximately $25 \mathrm{~cm}$ FL per year during those first years of life. In older specimens, the size increments became smaller as growth slowed down.

A significant linear relationship was estimated between the size of the specimens and the radius of their vertebrae. Nonetheless, no age verification or validation was made during this study, so our assumption of annual growth band formation remains unvalidated. Previous studies on other hammerhead shark species have discussed this issue, with different criteria and results. For the scalloped hammerhead, Chen et al. (1990) assumed that two pairs of bands per year were being deposited in the Taiwanese population, while Piercy et al. (2007) assumed a pattern of one pair of bands per year in the NW Atlantic. For the great hammerhead shark, Sphyrna mokarran, Passerotti et al. (2010) validated the annual deposition pattern of the growth bands with the bomb radiocarbon technique, demonstrating that indeed one pair of bands (one opaque and one translucent) was being deposited annually.
For the bonnethead (Sphyrna tiburo) in the Gulf of Mexico, Parsons (1993) also validated the periodicity of growth band deposition as one pair of bands per year by analysing vertebrae of specimens marked with oxytetracycline. However, firm confirmation of this annual pattern is still lacking for S. zygaena, and future work on the species should address this issue.

The growth parameters presented in this paper are, to our knowledge, the first ones available for S. zygaena in the Eastern Equatorial Atlantic Ocean. These results meet some of the recent recommendations requested by ICCAT for more studies focused on the life history parameters of poorly known oceanic sharks. These parameters can now be incorporated into stock assessment models to help to provide future advice and recommendations for the sustainable utilization of those resources.

Acknowledgements. Samples were collected as part of the SELECTPAL project (Programa PROMAR Proj. 31-03-05-FEP-1) and EU Data Collection Framework. Thanks are due to the crews of the FV Príncipe das Marés and FV Alma Lusa, and to the technicians (I. Ribeiro, M. Cerqueira and J.R. Táta) for collecting the samples. The authors are grateful to G. Burgess and Dr. A. Piercy (Florida Museum of Natural History) for providing recommendations on processing the vertebra. Thanks are also due to the many student volunteers from the Univ. Florida that helped cleaning the vertebrae in the Florida Program for Shark Research laboratory. Rui Coelho was supported by a grant from FCT (Ref: BDP 40523/2007) co-funded by "POCI-2010 Programa Operacional Ciência e Inovação 2010" and "FSE Fundo Social Europeu". Joana Fernandez-Carvalho holds a grant from FCT (Ref: BD 60624/2009). 


\section{References}

Abramoff M.D., Magalhaes P.J., Ram S.J., 2004, Image Processing with ImageJ. Biophotonics International, 11, 36-42.

Anislado-Tolentino V., Cabello M.G., Linares F.A., Mendoza C.R., 2008, Age and growth of the scalloped hammerhead shark, Sphyrna lewini (Griffith and Smith, 1834) from the Southern coast of Sinaloa, Mexico. Hidrobiologica 18, 31-40.

Anislado-Tolentino V., Robinson-Mendoza C., 2001, Age and growth for the scalloped hammerhead shark, Sphyrna lewini (Griffith and Smith, 1834) along the Central Pacific Coast of Mexico. Cienc. Mar. 27, 501-520.

Barker M.J., Schluessel V., 2005, Managing global shark fisheries: suggestions for prioritizing management strategies. Aquat. Conserv. Mar. Freshw. Ecosyst. 15, 325-347.

Beamish R.J., Fournier D.A., 1981, A method for comparing the precision of a set of age determinations. Can. J. Fish. Aquat. Sci. 38, 982-983.

Branstetter S., 1987, Age, growth and reproductive biology of the silky shark, Carcharhinus falciformis, and the scalloped hammerhead, Sphyrna lewini, from the Northwestern Gulf of Mexico. Environ. Biol. Fishes 19, 161-173.

Buencuerpo V., Rios S., Moron J., 1998, Pelagic sharks associated with the swordfish, Xiphias gladius, fishery in the eastern North Atlantic Ocean and the Strait of Gibraltar. Fish. Bull. 96, 667685.

Cailliet G.M., Martin L.K., Kusher D., Wolf P., Welden B.A., 1983, Techniques for enhancing vertebral bands in age estimation of California elasmobranchs. In: Prince E.D., Pulos L.M. (Eds.) Proc. International workshop on age determination of oceanic pelagic fishes: tunas, billfishes, sharks. NOAA Tech. Rep. NMFS 8, pp. 157-165.

Cailliet G.M., Goldman K.J., 2004, Age determination and validation in chondrichthyan fishes. In: Carrier J., Musick A., Heithaus M. (Eds.) The biology of sharks and their relatives, Boca Raton, CRC Press, pp. 399-447.

Campana S.E., 2001, Accuracy, precision and quality control in age determination, including a review of the use and abuse of age validation methods. J. Fish Biol. 59, 197-242.

Cerrato R. M., 1990, Interpretable statistical tests for growth comparisons using parameters in the von Bertalanffy equation. Can. J. Fish. Aquat. Sci. 47, 1416-1426.

Chang W.Y.B., 1982, A statistical method for evaluating the reproducibility of age determinations. Can. J. Fish. Aquat. Sci. 39, $1208-1210$.

Chen C.T., Leu T.C., Joung S.J., Lo N.C.H., 1990, Age and growth of the scalloped hammerhead, Sphyrna lewini, in Northeastern Taiwan waters. Pac. Sci. 44, 156-170.

Clarke S.C., McAllister M.K., Milner-Gulland E.J., Kirkwood G.P., Michielsens C.G.J., Agnew D.J., Pikitch E.K., Nakano H., Shivji M.S., 2006, Global estimates of shark catches using trade records from commercial markets. Ecol. Lett. 9, 1115-1126.

Compagno L.J.V., 1984, Sharks of the world. An annotated and illustrated catalogue of shark species known to date. Part 2. Carcharhiniformes. Rome, FAO.

Cortés E., 2000, Life history patterns and correlations in sharks. Rev. Fish. Sci. 8, 299-344.
Cortés E., Arocha F., Beerkircher L., Carvalho F., Domingo A., Heupel M., Holtzhausen H., Santos M.N., Ribera M., Simpfendorfer C., 2010, Ecological risk assessment of pelagic sharks caught in Atlantic pelagic longline fisheries. Aquat. Living Resour. 23, 25-34.

Goldman K.J., 2004, Age and growth of elasmobranch fishes. In: Musick J.A., Bonfil R. (Eds.) Elasmobranch fisheries management techniques, Singapore, APEC, pp. 97-132.

Harry A.V., Macbeth W.G., Gutteridge A.N., Simpfendorfer C.A., 2011, The life histories of endangered hammerhead sharks (Carcharhiniformes, Sphyrnidae) from the east coast of Australia. J. Fish Biol. 78, 2026-2051.

ICCAT, 2003, Resolution by ICCAT on the shark fishery. ICCAT Resolution 2003-10. URL: http://www.iccat.es/Documents/Recs/ compendiopdf-e/2003-10-e.pdf

ICCAT, 2004, Recommendation by ICCAT concerning the conservation of sharks caught in association with fisheries managed by ICCAT. ICCAT Recommendation 2004-10. URL: http://www. iccat.es/Documents/Recs/compendiopdf-e/2004-10-e.pdf

ICCAT, 2007, Supplemental recommendation by ICCAT concerning sharks. ICCAT Recommendation 2007-06. URL: http://www. iccat.es/Documents/Recs/compendiopdf-e/2007-06-e.pdf

Johnson A.G., 1979, A simple method for staining the centra of teleost vertebrae. NE Gulf Sci. 3, 113-115.

Katsanevakis S., 2006, Modelling fish growth: Model selection, multi-model inference and model selection uncertainty. Fish. Res. 81, 229-235.

Kimura D.K., 1980, Likelihood methods for the von Bertalanffy growth curve. Fish. Bull. 77, 765-773.

LaMarca M.S., 1966, A simple technique for demonstrating calcified annuli in the vertebrae of large elasmobranchs. Copeia 1966, 351-352.

Parsons G.R., 1993, Age determination and growth of the bonnethead shark Sphyrna tiburo: a comparison of two populations. Mar. Biol. 117, 23-31.

Passerotti M.S., Carlson J.K., Piercy A.N., Campana S.E., 2010, Age validation of great hammerhead shark (Sphyrna mokarran), determined by bomb radiocarbon analysis. Fish. Bull. 108, 346351.

Piercy A.N., Carlson J.K., Sulikowski J.A., Burgess G. H., 2007, Age and growth of the scalloped hammerhead shark, Sphyrna lewini, in the north-west Atlantic Ocean and Gulf of Mexico. Mar. Freshw. Res. 58, 34-40.

Piercy A.N., Carlson J.K., Passerotti M.S., 2010, Age and growth of the great hammerhead shark, Sphyrna mokarran, in the northwestern Atlantic Ocean and Gulf of Mexico. Mar. Freshw. Res. 61, 992-998.

R Development Core Team, 2010, R: A language and environment for statistical computing. Vienna, R Foundation for Statistical Computing. http://www.R-project.org.

Smith S.E., Au D.W., Show C., 1998, Intrinsic rebound potentials of 26 species of Pacific sharks. Mar. Freshw. Res. 49, 663-678.

Stevens J.D., Bonfil R., Dulvy N.K., Walker P.A., 2000, The effects of fishing on sharks, rays, and chimaeras (chondrichthyans), and the implications for marine ecosystems. ICES J. Mar. Sci. 57, 476494. 